\title{
The Rate of Intravenous Cocaine Administration Determines Susceptibility to Sensitization
}

\author{
Anne-Noël Samaha, Yilin Li, and Terry E. Robinson \\ Department of Psychology (Biopsychology Program), The University of Michigan, Ann Arbor, Michigan 48109-1109
}

The potential for addiction is thought to be greatest when drugs of abuse reach the brain rapidly, because this produces intense subjective pleasurable effects. However, the ability of drugs to induce forms of cellular plasticity related to behavioral sensitization may also contribute to addiction. Therefore, we studied the influence of rate of intravenous cocaine delivery on its ability to induce psychomotor sensitization. In one experiment, rotational behavior in rats with a unilateral 6-hydroxydopamine lesion was used as an index of psychomotor activation, and in a second experiment, locomotor activity in neurologically intact rats was used. Rapid (5-16 sec) intravenous infusions of cocaine induced robust psychomotor sensitization at all doses

The rate at which drugs of abuse exert their effects is associated with their abuse liability; thus, drugs, formulations, and routes of administration that yield the most rapid entry of a drug into the brain are potentially the most addictive (Gossop et al., 1992, 1994; Winger et al., 1992; Hatsukami and Fischman, 1996). This is one reason, for example, that smoked cocaine ("crack") is thought to be more addictive than powdered cocaine taken by insufflation (Hatsukami and Fischman, 1996). Rapid drug delivery is thought to promote abuse liability because of its influence on the positive subjective effects of drugs, consistent with reports that the positive effects of benzodiazepines (de Wit et al., 1993; Mumford et al., 1995), barbiturates (de Wit et al., 1992), and methylphenidate (Kollins et al., 1998) are greatest when these drugs are administered rapidly. For cocaine, evidence of a relationship between rate of drug delivery and its subjective effects is largely anecdotal. However, Abreu et al. (2001) recently compared the effects of a fixed dose of intravenous cocaine delivered over 2 , 15 , or $60 \mathrm{sec}$ and found that rapid rates of infusion produced the greatest subjective effects (e.g., "high," "liking," and "rush"; also see Fischman and Schuster, 1984).

The notion that rapidly administered cocaine not only produces greater subjective effects but also may lead to more avid drug-taking behavior is supported by studies showing that rapid intravenous drug delivery is most effective in supporting selfadministration behavior. With increasing rates of cocaine administration, rhesus monkeys increase their rate of operant responding and decrease operant responding when the rate of administration

\footnotetext{
Received Oct. 12, 2001; revised Dec. 20, 2001; accepted Jan. 28, 2002.

This research was supported by Grant R01 DA02494 from the National Institute on Drug Abuse. T.E.R. was supported by a Senior Scientist Award (K05 DA00473). We are greatly indebted to Dr. J. B. Justice Jr for computing the values illustrated in Figure 1.

Correspondence should be addressed to Dr. Terry E. Robinson, University of Michigan, Department of Psychology, East Hall, 525 East University, Ann Arbor, MI 48109-1109. E-mail: ter@umich.edu.

Copyright (ㄷ) 2002 Society for Neuroscience $0270-6474 / 02 / 223244-07 \$ 15.00 / 0$
}

tested $(0.5-2.0 \mathrm{mg} / \mathrm{kg})$. Treatments given over $25 \mathrm{sec}$ failed to induce sensitization at all doses tested. Treatments given over 50 or $100 \mathrm{sec}$ induced sensitization only at the highest dose tested. Thus, the rate of intravenous cocaine delivery has profound effects on the ability of cocaine to induce psychomotor sensitization. This suggests that the temporal dynamics of drug delivery to the brain is a critical factor in the ability of cocaine to induce forms of neuronal plasticity that may contribute to addiction.

Key words: cocaine; psychomotor sensitization; behavioral sensitization; intravenous; rate of infusion; 6-hydroxydopamine lesion; rat

is decreased (Balster and Schuster, 1973; Panlilio et al., 1998). Primates will also self-administer lower doses of cocaine if the drug is delivered more rapidly (Kato et al., 1987). Thus, it appears that the reinforcing efficacy of cocaine is greatest when it is administered rapidly. Furthermore, intravenously administered cocaine is more effective in establishing a conditioned place preference than cocaine administered intraperitoneally (Nomikos and Spyraki, 1988).

The subjective pleasurable and reinforcing effects of drugs certainly contribute to addiction, but it is important to remember that the transition to compulsive patterns of drug-seeking and drug-taking behavior is not necessarily a direct function of either their subjective pleasurable effects or their reinforcing efficacy (Robinson and Berridge, 1993, 2000). For example, drug-induced adaptations in the organization of brain systems that mediate the incentive motivational effects of drugs may be critical in the transition to addiction (Lett, 1989; Piazza et al., 1989; Horger et al., 1990; Robinson and Berridge, 1993, 2000). One behavioral manifestation of this class of drug-induced neuroadaptations is the phenomenon of psychomotor sensitization (Robinson and Berridge, 1993). We hypothesized, therefore, that susceptibility to sensitization might be enhanced by the rapid delivery of drugs to the brain. Interestingly, the influence of rate of drug delivery on sensitization has never been examined before. We report here that in rats, the rate of intravenous cocaine administration has profound effects on its ability to induce psychomotor sensitization.

\section{MATERIALS AND METHODS}

Subjects

Male Sprague Dawley rats weighing between 200 and $250 \mathrm{gm}$ on arrival were purchased from Harlan Sprague Dawley (Indianapolis, IN). All rats were housed individually in a climate-controlled colony room maintained on a 14/10 hr light/dark cycle (lights on at 8:00 A.M.). 


\section{Experiment 1}

Surgical procedures. The purpose of experiment 1 was to investigate the effects of rate of intravenous cocaine delivery on sensitization to the psychomotor activating effects of cocaine, as quantified by measuring rotational behavior in rats with a unilateral lesion of the nigrostriatal dopamine system (Ungerstedt and Arbuthnott, 1970). This particular index of psychomotor activation was used because it has been shown to be an especially sensitive indicator of psychomotor sensitization (Robinson, 1984; Crombag et al., 1999).

After 5-9 d of habituation to the animal colony, rats received a unilateral 6-hydroxydopamine (6-OHDA) lesion of the nigrostriatal dopamine pathway using procedures described previously (Robinson, 1984). Briefly, rats were pretreated with desipramine hydrochloride (15 $\mathrm{mg} / \mathrm{kg}$, i.p.) to protect noradrenergic terminals (Breese and Traylor, 1971) and were given atropine methyl nitrate $(5 \mathrm{mg} / \mathrm{kg}$, i.p.) before being anesthetized with sodium pentobarbital $(52 \mathrm{mg} / \mathrm{kg}$, i.p.; The Butler Company, Columbus, OH). Methoxyflurane (Schering-Plough Animal Health Corp., Union, NJ) was used as needed during surgery to maintain anesthesia. Approximately $30 \mathrm{~min}$ after the administration of desipramine, a 26 gauge stainless steel injector was lowered into the medial forebrain bundle and $4 \mu \mathrm{g}$ of 6-OHDA (dissolved in $8 \mu \mathrm{l}$ of a $0.9 \%$ $\mathrm{NaCl}$ /ascorbic acid solution) was inf used over an $8 \mathrm{~min}$ period at a flow rate of $0.5 \mu \mathrm{l} / \mathrm{min}$. The injector was left in place an additional $2 \mathrm{~min}$ to minimize diff usion upward in the injector tract. One-half of the animals received a lesion in the left hemisphere and one-half received a lesion in the right hemisphere.

After 10-14 d of recovery, the development of denervation supersensitivity was assessed by administering apomorphine $(0.05 \mathrm{mg} / \mathrm{kg}$, s.c., into the nape of the neck) to all rats and measuring contraversive rotational behavior. At this dose, apomorphine produces marked circling behavior only if animals are depleted of $>90 \%$ of the dopaminergic input to the striatum (Marshall and Ungerstedt, 1977). The animals were observed $10 \mathrm{~min}$ after the apomorphine injection, and rats that did not meet a screening criterion of more than five full rotations in a $1 \mathrm{~min}$ period were excluded from the experiment.

After the apomorphine screen, intravenous catheters were implanted in all rats using procedures described previously (Weeks, 1972; Crombag et al., 1996). The catheters were constructed from SILASTIC (DowCorning, Midland, MI) tubing [0.30 $\mathrm{mm}$ inner diameter (ID), $0.64 \mathrm{~mm}$ outer diameter (OD)], two sizes of polyethylene (PE) tubing $(0.38 \mathrm{~mm}$ ID, $1.09 \mathrm{~mm}$ OD and $0.28 \mathrm{~mm}$ ID, $0.61 \mathrm{~mm}$ OD), and a backport consisting of a 26 gauge piece of stainless steel tubing inserted into a blunted 16 gauge needle affixed to a circular piece of mesh wire with dental cement (Caine et al., 1993). Briefly, rats were anesthetized with sodium pentobarbital $(52 \mathrm{mg} / \mathrm{kg}$, i.p.), and the catheter was placed such that the silicone end was inserted into the right external jugular vein and the backport exited dorsally between the animal's shoulder blades. The catheters were then flushed with $0.1 \mathrm{ml}$ of gentamicin $(50 \mathrm{mg} / \mathrm{kg})$ and 0.1 $\mathrm{ml}$ of heparin solution $(30 \mathrm{U} / \mathrm{ml}$, in $0.9 \%$ sterile bacteriostatic saline) to prevent occlusions and potential microbial buildup in the catheter. All drugs were purchased from Sigma (St. Louis, MO) unless otherwise noted.

After catheter implantation, animals were allowed to recover for $3 \mathrm{~d}$ before testing began. During this period and throughout the duration of the experiment, catheters were manually flushed once daily with $0.1 \mathrm{ml}$ of heparin solution. The day before testing began, catheters were screened for patency by injecting $0.1 \mathrm{ml}$ (i.v.) of the short-acting barbiturate Pentothal (thiopental sodium, $20 \mathrm{mg} / \mathrm{ml}$ in sterile water). Rats who failed to become ataxic within $5 \mathrm{sec}$ were excluded from the experiment. The same patency test was performed the day after the drug treatment and on the day after the challenge test day.

Apparatus. The test cages consisted of circular plastic buckets $25 \mathrm{~cm}$ in diameter and $36 \mathrm{~cm}$ in height, the floors of which were covered with granulated corncob bedding. Each bucket was equipped with a photocellbased automated rotometer that recorded quarter, half, and full turns in each direction using an XT-based personal computer (McFarlane et al., 1992). A full turn was defined as four consecutive $90^{\circ}$ turns in the same direction. Each rat was tethered to a homemade liquid swivel (Brown et al., 1976) via a stainless steel cable. The swivel was mounted on a counterbalanced arm allowing the animals to move unhindered in the apparatus. A length of PE20 tubing connected the swivel to a $1.0 \mathrm{ml}$ syringe mounted on a Harvard Apparatus (Holliston, MA) syringe pump. A second length of PE20 tubing connected the swivel to each animal's catheter and served as the drug/vehicle infusion line. The pumps were programmed to inf use a fixed unit dose of $1 \mathrm{mg} / \mathrm{kg}$ cocaine over $3(300 \mu \mathrm{l} / \mathrm{min}), 9(100 \mu \mathrm{l} / \mathrm{min}), 16(50 \mu \mathrm{l} / \mathrm{min})$, or $34 \sec (25$ $\mu \mathrm{l} / \mathrm{min})$.

\section{Groups and procedures}

Pretreatment phase. After the unilateral 6-OHDA lesion and intravenous catheter implantation, the animals were assigned randomly to one of six groups. Initially all animals received intravenous infusions of either saline or $1.0 \mathrm{mg} / \mathrm{kg}$ cocaine: four groups received cocaine inf usions over either $3,9,16$, or $34 \mathrm{sec}$, and two control groups received saline inf usions over 3 or $34 \mathrm{sec}$, according to the following procedures. On each test day, the experimenter entered the testing room and filled the infusion lines, consisting of a length of PE20 tubing, with $10 \mu \mathrm{l}$ of $0.9 \% \mathrm{NaCl}$ solution or $10 \mu \mathrm{l}$ of cocaine $(1.0 \mathrm{mg} / \mathrm{kg}$ dissolved in $0.9 \% \mathrm{NaCl}$ solution). The remainder of the infusion line was filled with saline solution, which was separated from the drug solution by a small air bubble to prevent diff usion. The catheters were manually flushed with $0.1 \mathrm{ml}$ of heparin to clear potential obstructions before being placed in the testing cage, tethered to the liquid swivels via a lightweight flexible cable, and connected to the drug/saline infusion lines. A $30 \mathrm{~min}$ habituation period followed, during which time animals were left undisturbed and baseline levels of rotational behavior were monitored in $3 \mathrm{~min}$ intervals. The pumps in the testing room were then activated so that all animals received their injection simultaneously, regardless of infusion rate. Each infusion consisted of an initial $17 \mu \mathrm{l}$ of heparin (volume of the catheter) followed by $10 \mu \mathrm{l}$ of cocaine or saline followed by an additional $33 \mu \mathrm{l}$ of heparin. Thus, the total infusion volume was held constant at $60 \mu \mathrm{l}$ over the four infusion rates. After the infusion, rotational behavior was quantified for $21 \mathrm{~min}$ in $3 \mathrm{~min}$ intervals. After the test session, animals were disconnected from their tethers and returned to their home cages. This procedure was repeated for 7 consecutive days.

Withdrawal and cocaine challenge. After the last treatment, animals remained drug-free for $5 \mathrm{~d}$, during which time their catheters were manually flushed once daily with a heparin solution as described above. On day 6 after the last drug/saline treatment, all animals were tested for the expression of sensitization using the same procedures as described above, except that one-half of the animals in all groups (including animals previously treated with saline) received a challenge intravenous inf usion of $1.0 \mathrm{mg} / \mathrm{kg}$ cocaine over $3 \mathrm{sec}$, and the other half received the challenge infusion over $34 \mathrm{sec}$. One day later, animals previously challenged with a cocaine infusion over $3 \mathrm{sec}$ were now inf used over $34 \mathrm{sec}$, and vice versa. Behavior was recorded for $21 \mathrm{~min}$ in $3 \mathrm{~min}$ intervals after the infusion on each of the 2 challenge days.

\section{Experiment 2}

In experiment 1 , the influence of rate of infusion on the development of behavioral sensitization to cocaine was examined in rats with a unilateral 6-OHDA lesion of the nigrostriatal dopamine pathway, using rotational behavior as the index of psychomotor activation. The purpose of experiment 2 was to investigate this relationship in neurologically intact animals, using locomotor activity as an index of psychomotor activation, as well as to examine the interaction between dose of cocaine and rate of infusion.

Behavioral measures. The locomotor-activating effects of cocaine were measured by placing the animals in the circular testing cages described above, and the same photocell-based automated rotometers described in experiment 1 were used to record the total number of $90^{\circ}$ turns to the left and to the right. This method essentially divides the circular environment into four quadrants, and total quadrant entries (right/left combined) were used as an index of locomotor activity.

Surgical procedures. Animals were anesthetized with a mixture of ketamine, xylazine, and acepromazine $(77 / 1.5 / 1.5 \mathrm{mg} / \mathrm{ml}$, i.p., at 0.1 $\mathrm{ml} / 100 \mathrm{gm}$ of body weight), and intravenous catheters were implanted as described in experiment 1 .

\section{Groups and procedures}

Pretreatment phase. After intravenous catheter implantation, animals were assigned to their respective conditions. All animals received an intravenous inf usion of either PBS or $0.5,1.0$, or $2.0 \mathrm{mg} / \mathrm{kg}$ cocaine in the circular test cages every 3-4 d for a total of five inf usions, using the same procedures as in experiment 1 . The experimental groups received cocaine infusions over $5(142 \mu \mathrm{l} / \mathrm{min}), 25(27.4 \mu \mathrm{l} / \mathrm{min}), 50(13 \mu \mathrm{l} / \mathrm{min})$, or $100 \mathrm{sec}(6.4 \mu \mathrm{l} / \mathrm{min})$, and two control groups received vehicle inf usions over 5 or $100 \mathrm{sec}$.

Withdrawal and cocaine challenge. Four days after the last treatment, all groups (including animals previously treated with vehicle) received a 


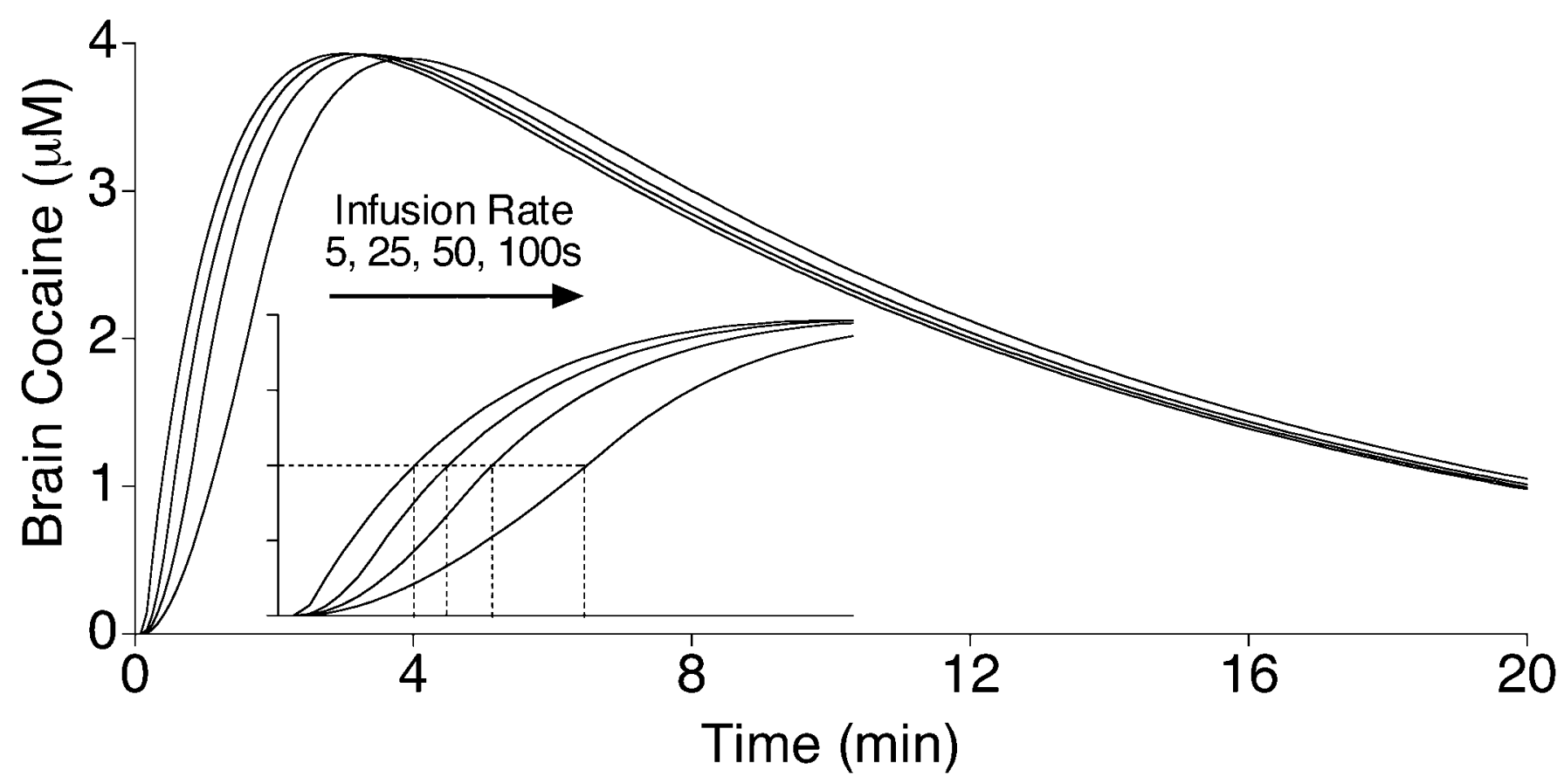

Figure 1. A pharmacokinetic model developed by Pan et al. (1991) was used to estimate brain concentrations of cocaine (micromolar concentrations) in a $300 \mathrm{gm}$ rat over a $20 \mathrm{~min}$ period after an intravenous injection of $1 \mathrm{mg} / \mathrm{kg}$ cocaine over 5, 25, 50, or 100 sec (lines from left to right, respectively). The inset shows the same curves, but with the time line expanded to show just the first 3 min. The dashed lines in the inset indicate the time for brain concentrations to reach half maximum after different rates of infusion, based on this model. Note that according to this model, there would be no effect of infusion rate on the maximal brain concentrations of cocaine over the range of conditions used in the experiments reported here. These curves were generously provided by Dr. J. B. Justice Jr, based on the report by Pan et al. (1991) (see Materials and Methods).

challenge intravenous infusion of $0.75 \mathrm{mg} / \mathrm{kg}$ cocaine over $10 \mathrm{sec}$ to examine the expression of sensitization.

\section{Rationale for doses and infusion rates}

The doses of cocaine used in these experiments $(0.5-2.0 \mathrm{mg} / \mathrm{kg})$ were chosen for two reasons. First, they span the range of intravenous doses previously found to be effective in producing both psychomotor activation and psychomotor sensitization (Browman et al., 1998). Second, these doses are within the range often used in studies of cocaine selfadministration behavior (Sizemore et al., 1997). The range of infusion times we used (3-100 sec) was chosen because it spans rates (1) often used in studies of cocaine self-administration behavior and (2) shown previously to influence self-administration behavior. For example, in their study on the role of infusion rate on cocaine self-administration, Balster and Schuster (1973) used infusion rates between 5 and $100 \mathrm{sec}$. These rates also span the range shown to influence the subjective effects of cocaine in humans (Abreu et al., 2001).

In addition, we wanted to study a range of infusion rates that produced different rates of cocaine delivery into the brain but, importantly, did not differ in the peak brain concentrations of cocaine achieved. Otherwise, it would be difficult to dissociate effects attributable to the effective dose achieved versus those attributable to the temporal dynamics of cocaine delivery. This is the problem in comparing, for example, intravenous and intraperitoneal administrations (Porrino, 1993). The temporal dynamics of cocaine delivery to the brain over the range of conditions used here were estimated using a pharmacokinetic model developed by Pan et al. (1991). Pan et al. (1991) used microdialysis to measure both the plasma and the brain concentrations of cocaine, given intraperitoneally or intravenously, to control rats or sensitized rats. They then estimated the relevant pharmacokinetic parameters by fitting a two-compartment open model to the data using nonlinear regression. The equations for the model and the parameter estimates are given in the study by Pan et al. (1991). This model (based on intravenous infusions) was used to generate the curves shown in Figure 1, using a program provided by Dr. J. B. Justice Jr. (Emory University, Atlanta, GA), with the sampling rate set at 12 points per second (faster rates did not change the curves). Figure 1 shows the estimated brain concentrations of cocaine, based on the model, after an injection of $1.0 \mathrm{mg} / \mathrm{kg}$ delivered over $5,25,50$, or $100 \mathrm{sec}$ (the curves are the same for 0.5 and $2.0 \mathrm{mg} / \mathrm{kg}$, except for peak level attained). It is obvious from inspection of Figure 1 that varying the rate of inf usion between 5 and $100 \mathrm{sec}$ should have no effect on the peak brain concentrations of cocaine. The inset in Figure 1 shows an expanded time scale ( $3 \mathrm{~min}$ ) to better illustrate the estimated time to achieve half-maximum levels of cocaine in the brain. The time to half maximum was estimated to vary by approximately twofold over the range of doses and infusion rates used here (from $43 \mathrm{sec}$ for a $5 \mathrm{sec}$ infusion to $97 \mathrm{sec}$ for a $100 \mathrm{sec}$ infusion). In summary, this pharmacokinetic model suggests that we achieved our goal of spanning a range of inf usion rates that produced the same peak brain levels of cocaine, while yielding different rates of cocaine delivery to the brain (Fig. 1).

\section{RESULTS}

\section{Experiment 1}

Figure 2 shows the time course of rotational behavior after the first and seventh infusions of cocaine administered over 3, 9, 16, or $34 \mathrm{sec}$. There was a significant interaction between treatment day and rotations in all groups, indicating a significant change in the behavioral response to cocaine from day 1 to day 7 at all infusion rates tested (see figure legends for statistics). Although all groups showed sensitization using this within-subjects analysis, it is also obvious from Figure 2 that the change in drug response in animals given cocaine over $34 \mathrm{sec}$ was relatively small. Indeed, the rotational response on day 7 was significantly smaller in animals inf used over $34 \mathrm{sec}$ relative to all other groups.

Figure 3 shows the effects of treatment condition on the behavioral response to a $1.0 \mathrm{mg} / \mathrm{kg}$ cocaine challenge infusion administered over 3 or $34 \mathrm{sec}$. There was no effect of rate of saline infusion on behavior; therefore, the two saline-pretreated groups were pooled to form a single control group. For this betweensubjects analysis, sensitization is indicated by a response that is greater than that in saline-pretreated control animals. Regardless 


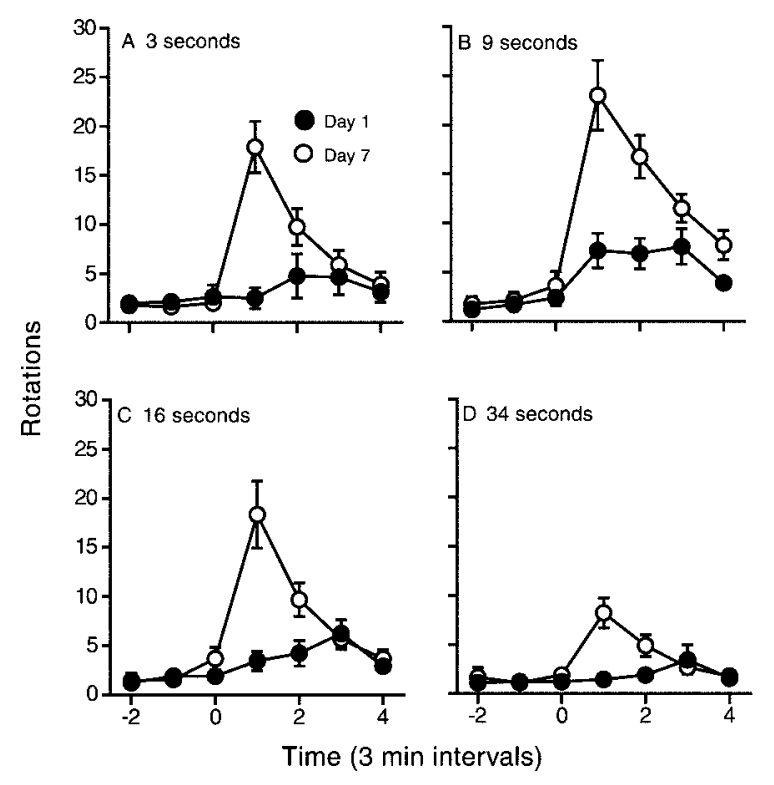

Figure 2. The mean $( \pm \mathrm{SEM})$ number of rotations over time (3 min intervals) produced by an intravenous inf usion of $1 \mathrm{mg} / \mathrm{kg}$ cocaine given over $3(n=9), 9(n=10), 16(n=9)$, or $34(n=9)$ sec on day 1 and day 7 of treatment. For all treatment conditions, there was a significant increase in the behavioral response to cocaine between days 1 and 7 (two-way ANOVAs; $A$, main effect of treatment day, $F_{\mathrm{t}(1,16)}=5.35, p=$ 0.03 ; treatment day $\times$ time interaction, $F_{\mathrm{i}(3,48)}=17.96, p<0.0001 ; B$, $F_{\mathrm{t}(1,18)}=4.18, p=0.06 ; F_{\mathrm{i}(3,54)}=8.46, p=0.0001 ; C, F_{\mathrm{t}(1,17)}=8.88, p=$

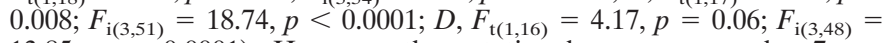
$13.85, p<0.0001)$. However, the rotational response on day 7 was significantly smaller in the $34 \mathrm{sec}$ group relative to all other groups (two-way ANOVAs; main effects of rate of infusion, $F_{(1,15-17)}=7.36-$ $8.11, p<0.03)$.

of the rate at which the challenge infusion was administered, animals previously treated with cocaine infusions over 3,9 , or 16 sec showed a significantly greater locomotor response than salinetreated controls, confirming that these groups were sensitized. Animals treated repeatedly with cocaine infusions over $34 \mathrm{sec}$ did not differ statistically from controls.

\section{Experiment 2}

Figure 4 shows the locomotor response (quadrant entries), averaged over 15 min after the first intravenous inf usion of cocaine, as a function of dose and rate of administration. As in experiment 1 , there was no effect of rate of vehicle administration on behavior; thus, the two control groups were combined. There was a significant and comparable increase in behavior as a function of increasing dose for all rates of infusion. However, the dose-effect function in rats given cocaine over $5 \mathrm{sec}$ was shifted to the left relative to all other groups, which did not differ from one another.

Figure 5 shows the response to a challenge infusion of 0.75 $\mathrm{mg} / \mathrm{kg}$ cocaine over $10 \mathrm{sec}$ as a function of previous treatment condition. Panels on the right show the time course of the locomotor response on the day of the challenge test as a function of treatment condition. It can be seen that sensitization was characterized both by a larger peak response to the drug and by a more rapid onset of the behavioral response. A more rapid onset of drug effect is a hallmark of sensitization (for review, see Segal and Schuckit, 1983; Carey and Gui, 1998). Figure 5, $A, C$, and $E$, summarizes these data, illustrating peak drug response (first $6 \mathrm{~min}$ ). Animals previously treated with $0.5 \mathrm{mg} / \mathrm{kg}$ cocaine over $5 \mathrm{sec}$ were significantly more active in response to the challenge inf usion than vehicle-

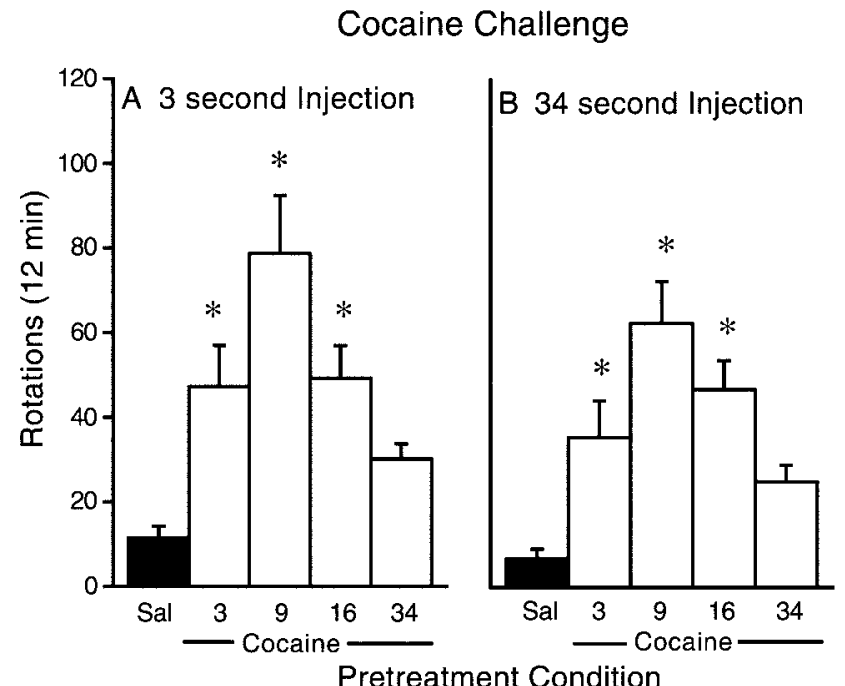

Figure 3. The mean $(+\mathrm{SEM})$ number of rotations (averaged over 12 $\mathrm{min}$ ) in response to a challenge inf usion of $1 \mathrm{mg} / \mathrm{kg}$ cocaine administered intravenously over $3 \mathrm{sec}(A)$ or $34 \mathrm{sec}(B)$ in rats pretreated with saline $(\mathrm{Sal} ; n=8)$ or $1 \mathrm{mg} / \mathrm{kg}$ cocaine over $3(n=7), 9(n=7), 16(n=9)$, or $34(n=7)$ sec. Animals previously treated with intravenous cocaine infusions over 3,9 , or $16 \mathrm{sec}$ differed significantly from the salinepretreated control group (one-way ANOVAs followed by Dunnett's tests; $\left.\alpha=0.05 ; A, F_{(4)}=8.97, p<0.0001 ; B, F_{(4)}=9.61, p<0.0001\right)$, but the group given injections over $34 \mathrm{sec}$ did not differ significantly from the vehicle control group (Dunnett's tests). *Different from the salinepretreated control group (Dunnett's tests).

First Injection

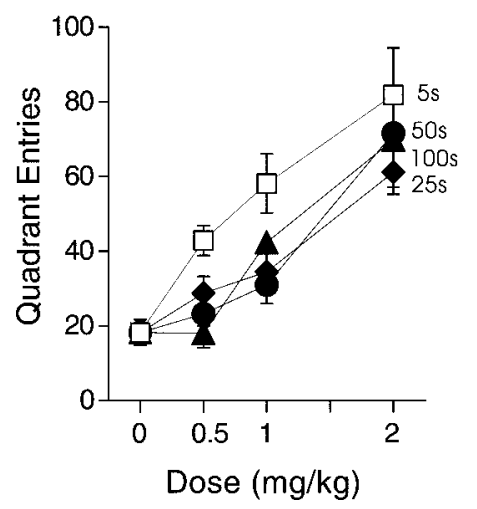

Figure 4. The mean $( \pm$ SEM) number of quadrant entries (averaged over $15 \mathrm{~min}$ ) in response to the first intravenous infusion of cocaine as a function of dose and rate of drug administration $(n=11-13)$. A significant effect of dose was found at all rates of infusion (two-way ANOVA; main effect of dose: $F_{(2,133)}=21.42, p<0.001$; main effect of rate of infusion: $F_{(3,6)}=2.93, p=0.04$; rate of infusion $\times$ dose: $F_{(6,133)}=0.38$, $p=0.89)$. The dose-effect function for the $5 \mathrm{sec}$ condition was shifted to the left relative to all other groups $\left(F_{(1,66-67)}=4.71-7.1 ; p=0.01-0.04\right)$, which did not differ from one another $(p>0.80)$.

treated controls $(A)$, confirming that this group became sensitized. However, animals repeatedly treated with $0.5 \mathrm{mg} / \mathrm{kg}$ over 25, 50, or $100 \mathrm{sec}$ did not differ significantly from the control group. Similarly, Figure $5 C$ shows that animals previously treated with $1.0 \mathrm{mg} / \mathrm{kg}$ cocaine over $5 \mathrm{sec}$ showed an enhanced response to the challenge infusion relative to controls, whereas animals previously treated with $1.0 \mathrm{mg} / \mathrm{kg}$ over 25,50 , or $100 \mathrm{sec}$ did not differ significantly from the control group. In contrast, Figure $5 E$ shows that animals repeatedly 


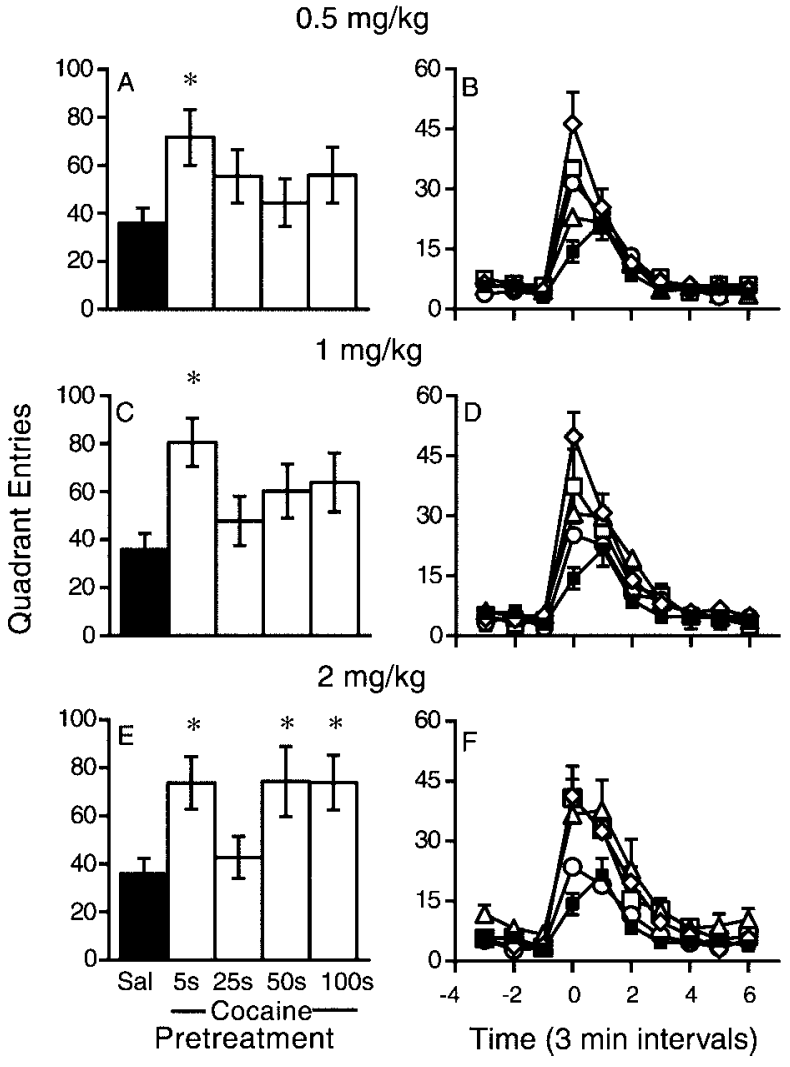

Figure 5. The locomotor response to a challenge inf usion of $0.75 \mathrm{mg} / \mathrm{kg}$ cocaine over $10 \mathrm{sec}$ as a function of previous treatment condition $(n=$ 6-13). Panels on the right depict the time course of the locomotor response. Left, The mean $( \pm \mathrm{SEM})$ peak number of quadrant entries (averaged over $6 \mathrm{~min}$ ) in response to the challenge infusion. Group comparisons were based on the peak values (one-way ANOVAs followed by Dunnett's tests, $\alpha=0.05$ ). When previously treated with $0.5 \mathrm{mg} / \mathrm{kg}$, only animals infused over $5 \mathrm{sec}$ differed from the vehicle-treated control group $\left(A, F_{(4)}=1.82, p=0.14\right.$, but Dunnett's comparison, $\left.p<0.05\right)$. Likewise, in rats treated with $1 \mathrm{mg} / \mathrm{kg}$, only the group inf used over $5 \mathrm{sec}$ differed from the control group $\left(B, F_{(4)}=3.52, p=0.01\right)$. All groups previously treated with $2 \mathrm{mg} / \mathrm{kg}(E)$ differed from the vehicle-treated control group $\left(F_{(4)}=3.58 ; p=0.01\right)$ except those previously inf used with this dose over $25 \mathrm{sec}$ (Dunnett's tests). *Different from the saline ( $\mathrm{Sal}$ )pretreated control group (Dunnett's tests). Sal, $\square ; 5 s, \diamond ; 25 s, \bigcirc ; 50 s, \triangle$; $100 s, \square$.

infused with $2.0 \mathrm{mg} / \mathrm{kg}$ cocaine over either 5 , 50, or $100 \mathrm{sec}$ were significantly more active than the control group, indicating that these groups were sensitized. However, animals repeatedly infused with this dose of cocaine over $25 \mathrm{sec}$ were indistinguishable from controls.

Figure 6 shows the same data as Figure 5, but plotted to illustrate the effects of previous cocaine dose on the peak locomotor response (first $6 \mathrm{~min}$ ) at each inf usion rate tested. It is clear from Figure $6 A$ that when given over $5 \mathrm{sec}$, all doses tested induced sensitization. In contrast, when administered over $25 \mathrm{sec}$, no dose tested induced sensitization (Fig. 6B). When cocaine was infused over 50 or $100 \mathrm{sec}$, there was an approximately linear increase in the behavioral response to the challenge inf usion (Fig. 6, $C$ and $D$, respectively), although only the groups treated with $2.0 \mathrm{mg} / \mathrm{kg}$ differed statistically from the control group (i.e., sensitized). Thus, the effects of past treatment dose on the locomotor response to a subsequent cocaine challenge varied as a function of infusion rate.
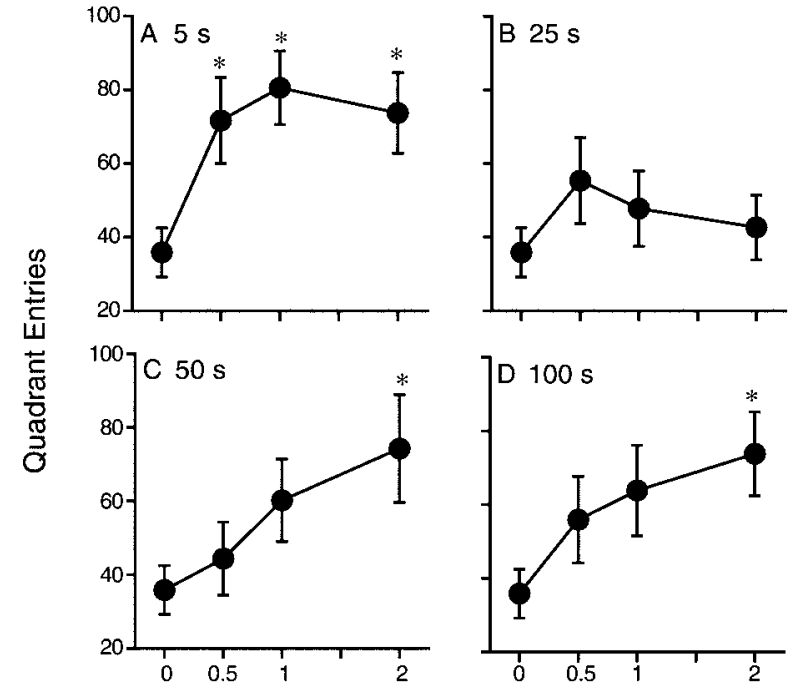

Pretreatment Dose $(\mathrm{mg} / \mathrm{kg})$

Figure 6. The mean $( \pm \mathrm{SEM})$ number of quadrant entries (averaged over $6 \mathrm{~min}$ ) in response to a challenge inf usion of $0.75 \mathrm{mg} / \mathrm{kg}$ cocaine over 10 $\mathrm{sec}$ as a function of previous cocaine dose and infusion rate $(n=6-13$; see Fig. 5 legend for statistical results). When administered over $5 \sec (A)$, all doses of cocaine tested induced a sensitized response to the challenge infusion relative to controls. When administered over $25 \mathrm{sec}(B)$, none of the doses tested induced a sensitized response to the challenge relative to controls. When administered over $50(C)$ or $100(D)$ sec, the doses tested produced an approximately linear increase in the locomotor response to the challenge infusion, but only the $2.0 \mathrm{mg} / \mathrm{kg}$ dose differed significantly from controls. *Differs from the vehicle-pretreated (dose of 0 ) control group (Dunnett's tests).

\section{DISCUSSION}

It is widely accepted that the rate at which cocaine enters the brain is an important determinant of both its positive subjective effects and its reinforcing effects (Gossop et al., 1992; Winger et al., 1992; Hatsukami and Fischman, 1996), although very few experimental studies directly address this issue. It has been suggested that the positive relationship between rate of drug delivery and subjective effects may contribute to abuse liability and addiction (Gossop et al., 1992; de Wit et al., 1993; Hatsukami and Fischman, 1996). However, another important effect of cocaine is its ability to induce long-lasting neuroadaptations in the organization of brain systems that mediate its psychomotor activating and incentive motivational effects (Robinson and Berridge, 1993, 2000; Nestler and Aghajanian, 1997), and some of these neuroadaptive processes have been related to the propensity for cocaine self-administration behavior (Piazza et al., 1989; Horger et al., 1990) and a cocaine-induced place preference (Lett, 1989). We hypothesized, therefore, that the rate of cocaine delivery may also influence its ability to induce sensitization. To address this question, we studied one behavioral manifestation of cocaineinduced neuroadaptations in brain reward systems that is thought to be related to addiction: the development of psychomotor sensitization (Robinson and Berridge, 1993, 2000).

In one study, rotational behavior in rats with a unilateral 6-OHDA lesion was used as an index of the psychomotor activating effects of cocaine (Ungerstedt and Arbuthnott, 1970; Robinson, 1984). When cocaine was infused intravenously over 3-16 sec, it produced robust behavioral sensitization. However, when infused over $34 \mathrm{sec}$, it produced only marginal sensitization (i.e., 
the effect was not statistically significant), as indicated by a challenge test given after a period of drug abstinence (modest but statistically significant sensitization was observed using a withinsubjects analysis during the drug treatment period). Similar results were obtained in a second experiment that used locomotor activity in neurologically intact rats as an index of psychomotor activation and in which both rate of drug delivery and dose were varied. At all doses tested, cocaine induced persistent sensitization (at least $4 \mathrm{~d}$ ) when it was administered over $5 \mathrm{sec}$. In contrast, all doses failed to induce sensitization when cocaine was administered over $25 \mathrm{sec}$. Surprisingly, when cocaine was given over 50-100 sec, its effects varied as a function of dose. At these infusion rates, there was a linear increase in the degree of sensitization as a function of treatment dose, although significant sensitization was seen only at the highest dose tested $(2.0 \mathrm{mg} / \mathrm{kg})$.

It is not clear what accounts for the effect that rate of intravenous cocaine delivery has on the induction of psychomotor sensitization. One obvious explanation is that maximal brain concentrations of cocaine may vary as a function of infusion rate, such that the fastest infusion rates result in higher peak brain concentrations of cocaine than the slower infusion rates. Given that the degree of sensitization is dose dependent (Kalivas et al., 1988; Browman et al., 1998), the effect of infusion rate could be just secondary to the achieved dose. There are, however, a number of reasons to believe that this does not explain the results reported here. First, on the basis of pharmacokinetic modeling (see Materials and Methods and Fig. 1), the peak brain concentrations of cocaine should not differ over the range of infusion rates shown here to influence the induction of sensitization. Second, this explanation cannot account for the fact that the fastest infusion rate $(5 \mathrm{sec})$ was very effective in inducing sensitization, an intermediate infusion rate $(25 \mathrm{sec})$ was ineffective, but even slower inf usion rates (50-100 sec) were again effective, at least at the highest dose tested. Third, varying infusion rates between 25 and $100 \mathrm{sec}$ had no effect on the acute dose-locomotor effect functions. This suggests that the primary neuropharmacological effects of cocaine (including brain concentrations of cocaine) did not vary over this range of infusion rates, although the ability of cocaine to induce sensitization varied greatly over this range of infusion rates. This is reminiscent of a report by Volkow et al. (2000) showing that in humans, smoked and intranasal cocaine produced equivalent plasma concentrations of cocaine and blockade of dopamine transporters, but smoked cocaine produced greater self-reports of "high." Therefore, our results are not consistent with a hypothesis that the effect of infusion rate is simply secondary to achieved dose.

Of course, varying the intravenous infusion rate would influence the rate of cocaine entry into the brain (Fig. 1, inset). Presumably this would influence the temporal pattern of monoamine transporter occupancy, the temporal pattern of monoamine accumulation in the synapse, and eventually, the temporal dynamics of monoamine receptor occupancy. The implication of these results, therefore, is that the temporal dynamics of monoamine receptor occupancy may be a critical variable in initiating whatever cascade of intracellular processes is necessary for the persistent neurobiological adaptations underlying behavioral sensitization. What is especially interesting is the notion that very small changes in the temporal dynamics of monoamine transporter occupancy (over tens of seconds) could have such profound effects on this form of neurobehavioral plasticity. We should stress, however, that contrary to our initial hypothesis, there does not appear to be a simple linear relationship between the rate of rise of brain cocaine and susceptibility to sensitization. For example, on the basis of the pharmacokinetic model (Fig. 1), we estimated that the initial rate of rise in brain cocaine produced by $2.0 \mathrm{mg} / \mathrm{kg}$ given over $25 \mathrm{sec}$ would be more than twice that produced by $0.5 \mathrm{mg} / \mathrm{kg}$ given over $5 \mathrm{sec}$, but only the latter induced sensitization. The nature of the relationship between the temporal dynamics of cocaine delivery and sensitization remains to be determined. Nevertheless, our results are consistent with reports that the temporal pattern of synaptic activation is important in producing other forms of cellular plasticity, such as longterm potentiation (Larson et al., 1986; Greenstein et al., 1988; Tsukada et al., 1994).

The rise in extracellular dopamine produced by cocaine is tightly coupled to brain concentrations of cocaine (Nicolaysen et al., 1988). Therefore, given the pharmacokinetic model of Pan et al. (1991), we would not expect that a variation in infusion rate over the range used here would influence the magnitude of the dopaminergic response to cocaine (although the temporal profile of the response should be affected). Indeed, it has been found that the peak dopamine response in the nucleus accumbens, assessed with microdialysis, is the same when $1.0 \mathrm{mg} / \mathrm{kg}$ cocaine is given intravenously over 6 or $150 \mathrm{sec}$ (Zernig, 1997). We are not aware of any other studies that directly compare the neurobiological effects of different rates of intravenous cocaine delivery, but Porrino (1993) compared the effect of intravenous versus intraperitoneal cocaine on cerebral glucose utilization. She found that over a wide range of doses, intraperitoneal cocaine induced glucose utilization primarily in structures related to nigrostriatal circuitry but failed to change glucose utilization in components of the mesocorticolimbic system. In contrast, intravenous cocaine increased glucose utilization not only in the nigrostriatal system but also in the medial frontal cortex, nucleus accumbens, olfactory tubercle, and lateral habenula. Porrino (1993) concluded that "cocaine activates different neuronal circuitry depending on the route by which it is administered" and that this difference was most likely the result of pharmacokinetic (i.e., rate of drug delivery) and not dose-related factors. It is possible, therefore, that the ability of rapidly administered cocaine to preferentially activate mesocorticolimbic circuitry (Porrino, 1993) may be related to the facilitation of psychomotor sensitization reported here.

Another intriguing implication of the present findings is raised by the fact that the intermediate infusion rates (e.g., $25 \mathrm{sec}$ ) failed to induce sensitization at any dose studied and that the doseeffect functions for the various infusion rates were so different. These results prompt the speculation that the neurobiological adaptations underlying a sensitized behavioral response in rats given cocaine over $5 \mathrm{sec}$ are different from those responsible for a sensitized behavioral response in rats given cocaine over 50 $100 \mathrm{sec}$. There are many different neuroadaptive processes that could result in an enhanced behavioral response to a drug challenge, and different neuroadaptive processes could be evoked under different conditions. Of course, most studies of behavioral sensitization involve the intraperitoneal administration of psychostimulant drugs, which would result in relatively slow drug absorption compared with a $5 \mathrm{sec}$ intravenous infusion (Pan et al., 1991). It is possible, therefore, that much of what is known about the neurobiology of sensitization may not apply if sensitization is induced by modes of drug administration that result in the very rapid entry of drugs into the brain. This may be an important issue in thinking about how sensitization-related neuroadaptations contribute to the process of addiction, because addicts tend 
to prefer drugs, formulations, and routes of administration that lead to the rapid uptake of drugs into the brain.

We close with two thoughts: (1) The reason why drugs that are rapidly delivered to the brain are especially addictive may be not because this enhances their positive subjective effects, or even their reinforcing effects, but rather because this increases their ability to induce sensitization-related adaptations in brain regions that mediate their incentive motivational effects (Robinson and Berridge, 1993, 2000). (2) Drugs of abuse may produce different cellular adaptations depending on the temporal pattern of drug delivery. That is, although the behavioral manifestations of drug experience-dependent changes in brain organization (psychomotor sensitization in this case) may appear similar in animals given cocaine rapidly or more slowly, the nature of the cellular adaptations responsible for the enhanced behavioral response may vary as a function of the temporal pattern of drug delivery. If this is true, it will be critical in future studies on the neurobiology of sensitization to use procedures that capture the rapid onset of drug effects typical in the addict.

\section{REFERENCES}

Abreu ME, Bigelow GE, Fleisher L, Walsh SL (2001) Effect of intravenous injection speed on responses to cocaine and hydromorphone in humans. Psychopharmacology (Berl) 154:76-84.

Balster RL, Schuster CR (1973) Fixed-interval schedule of cocaine reinforcement: effect of dose and infusion duration. J Exp Anal Behav 20:119-129.

Breese GR, Traylor TD (1971) Depletion of brain noradrenaline and dopamine by 6-hydroxydopamine. Br J Pharmacol 42:88-99.

Browman KE, Badiani A, Robinson TE (1998) The influence of environment on the induction of sensitization to the psychomotor activating effects of intravenous cocaine in rats is dose-dependent. Psychopharmacology (Berl) 137:90-98.

Brown ZW, Amit Z, Weeks JR (1976) Simple flow-through swivel for infusions into unrestrained animals. Pharmacol Biochem Behav $5: 363-365$.

Caine SB, Lintz R, Koob GF (1993) Intravenous drug selfadministration techniques in animals. In: Behavioral neuroscience: a practical approach, Vol 2 (Sahgal A, ed), pp 117-143. New York: IRL at Oxford UP.

Carey R, Gui J (1998) Cocaine sensitization can accelerate the onset of peak cocaine behavioral effects. Pharmacol Biochem Behav 60:395-405.

Crombag HS, Badiani A, Robinson TE (1996) Signalled versus unsignalled intravenous amphetamine: large differences in the acute psychomotor response and sensitization. Brain Res 722:227-231.

Crombag HC, Mueller H, Browman KE, Badiani A, Robinson TE (1999) A comparison of two behavioral measures of psychomotor activation following intravenous amphetamine or cocaine: dose- and sensitization-dependent changes. Behav Pharmacol 10:205-213.

de Wit H, Bodker B, Ambre J (1992) Rate of increase of plasma drug level influences subjective response in humans. Psychopharmacology 107:352-358.

de Wit H, Dudish S, Ambre J (1993) Subjective and behavioral effects of diazepam depend on its rate of onset. Psychopharmacology 112:324-330.

Fischman MW, Schuster CR (1984) Injection duration of cocaine in humans. Fed Proc 43:570.

Gossop M, Griffiths P, Powis B, Strang J (1992) Severity of dependence and route of administration of heroin, cocaine and amphetamines. $\mathrm{Br} \mathrm{J}$ Addict 87:1527-1536.

Gossop M, Griffiths P, Powis B, Strang J (1994) Cocaine: patterns of use, route of administration, and severity of dependence. Br J Psychiatry 164:660-664.

Greenstein YJ, Pavlides C, Winson J (1988) Long-term potentiation in the dentate gyrus is preferentially induced at theta rhythm periodicity. Brain Res 438:331-334.

Hatsukami DK, Fischman MW (1996) Crack cocaine and cocaine hydrochloride: are the differences myth or reality? JAM A 276:1580-1588.

Horger BA, Shelton K, Schenk S (1990) Preexposure sensitizes rats to the rewarding effects of cocaine. Pharm Biochem Behav 37:707-711.

Kalivas PW, Duffy P, DuMars LA, Skinner C (1988) Behavioral and neurochemical effects of acute and daily cocaine administration in rats. J Pharmacol Exp Ther 245:485-492.

Kato S, Wakasa Y, Yanagita T (1987) Relationship between minimum reinforcing doses and injection speed in cocaine and pentobarbital self-administration in crab-eating monkeys. Pharmacol Biochem Behav 28:407-410.

Kollins SH, Rush CR, Pazzaglia PJ, Ali JA (1998) Comparison of acute behavioral effects of sustained-release and immediate-release methylphenidate. Exp Clin Psychopharmacol 6:367-374.

Larson J, Wong D, Lynch G (1986) Patterned stimulation at the theta frequency is optimal for the induction of hippocampal long-term potentiation. Brain Res 368:347-350.

Lett BT (1989) Repeated exposures intensify rather than diminish the rewarding effects of amphetamine, morphine, and cocaine. Psychopharmacology (Berl) 98:357-362.

Marshall JF, Ungerstedt U (1977) Supersensitivity to apomorphine following destruction of the ascending dopamine neurons: quantification using the rotational model. Eur J Pharmacol 41:361-367.

McFarlane DK, Martonyi BJ, Robinson TE (1992) An inexpensive automated system for the measurement of rotational behavior in small animals. Behav Res Methods Instrum Comput 24:414-419.

Mumford GK, Evans SM, Fleishaker JC, Griffiths RR (1995) Alprazolam absorption kinetics affects abuse liability. Clin Pharmacol Ther $57: 356-365$.

Nestler EJ, Aghajanian GK (1997) Molecular and cellular basis of addiction. Science 278:58-63.

Nicolaysen LC, Pan HT, Justice Jr JB (1988) Extracellular cocaine and dopamine concentrations are linearly related in rat striatum. Brain Res 456:317-323.

Nomikos GG, Spyraki C (1988) Cocaine-induced place conditioning: importance of route of administration and other procedural variables Psychopharmacology 94:119-125.

Pan HT, Menacherry S, Justice Jr JB (1991) Differences in the pharmacokinetics of cocaine in naive and cocaine-experienced rats. J Neurochem 56:1299-1306.

Panlilio LV, Goldberg SR, Gilman JP, Jufer R, Cone EJ, Schindler CW (1998) Effects of delivery rate and non-contingent infusion of cocaine on cocaine self-administration in rhesus monkeys. Psychopharmacology (Berl) 137:253-258.

Piazza PV, Deminière JM, Le Moal M, Simon H (1989) Factors that predict individual vulnerability to amphetamine self-administration. Science 245:1511-1513.

Porrino LJ (1993) Functional consequences of acute cocaine treatment depend on route of administration. Psychopharmacology 112:343-351.

Robinson TE (1984) Behavioral sensitization: characterization of enduring changes in rotational behavior produced by intermittent injections of amphetamine in male and female rats. Psychopharmacology 84:466-475.

Robinson TE, Berridge KC (1993) The neural basis of drug craving: an incentive-sensitization theory of addiction. Brain Res Brain Res Rev 18:247-291.

Robinson TE, Berridge KC (2000) The psychology and neurobiology of addiction: an incentive-sensitization view. Addiction 95 [Suppl 2]:S91-S117.

Segal DS, Schuckit MA (1983) Animal models of stimulant-induced psychosis. In: Stimulants: neurochemical, behavioral and clinical perspectives (Creese I, ed), pp 131-167. New York: Raven.

Sizemore GM, Gaspard TM, Kim SA, Walker LE, Vrana SL, Dworkin SI (1997) Dose-effect functions for cocaine self-administration: effects of schedule and dosing procedure. Pharmacol Biochem Behav 57:523-531.

Tsukada M, Aihara T, Mizuno M, Kato H, Ito K (1994) Temporal pattern sensitivity of long-term potentiation in hippocampal CA1 neurons. Biol Cybern 70:495-503.

Ungerstedt U, Arbuthnott GW (1970) Quantitative recording of rotational behavior in rats after 6-hydroxy-dopamine lesions of the nigrostriatal dopamine system. Brain Res 24:485-493.

Volkow ND, Wang GJ, Fischman MW, Foltin R, Fowler JS, Franceschi D, Franceschi M, Logan J, Gatley SJ, Wong C, Ding YS, Hitzemann R Pappas N (2000) Effects of route of administration on cocaine induced dopamine transporter blockade in the human brain. Life Sci 67:1507-1515.

Weeks JR (1972) Long-term intravenous infusions. In: Methods in psychobiology (Meyers RD, ed), pp 155-168. London: Academic.

Winger G, Hofmann FG, Woods JH (1992) A handbook on drug and alcohol abuse: the biomedical aspects. New York: Oxford UP.

Zernig G (1997) Rate of rise in brain concentration determines reinforcing strength of cocaine in only $63 \%$ of tested rats. NIDA Res Monogr 178:218. 